\title{
Continuous activity in cetaceans after birth
}

\section{The exceptional wakefulness of newborn whales and dolphins has no ill-effect on their development.}

All mammals previously studied take maximal rest or sleep after birth, with the amount gradually decreasing as theygrow to adulthood ${ }^{1,2}$, and adult fruitflies and rats die if they are forcibly deprived of sleep $p^{3,4}$. It has therefore been assumed that sleep is necessary for development and serves a vital function in adults. But we show here that, unlike terrestrial mammals, killer-whale and bottlenose-dolphin neonates and their mothers show little or no typical sleep behaviour for the first postpartum month, avoiding obstades and remaining mobile for 24 hours a day. We find that neonates and their mothers gradually increase the amount of time they spend resting to normal adult levels over a period of several months, but never exceed these levels. Our findings indicate either that sleep behaviour may not have the developmental and life-sustaining functions attributed to it, or that alternative mechanisms may have evolved in cetaceans.

Two adult female killer whales (Orcinus orca) and their calves were observed for 5 months after birth (for methods, see supplementary information). Adult orcas normally show distinct periods of immobility, which occupy 5-8 hours a day under baseline conditions, while floating at the surface or lying on the bottom of pools. Figure 1 a shows the suppression of typical rest behaviour in the mother for several months after birth and even less rest behaviour in the newborn over this period. The calves always rested less than their mothers and less than other adults (Fig. 1a), unlike all other mammals that have been studied. (For video, see supplementary information.)

We assayed blood concentrations of the hormone cortisol in three killer-whale mothers at 3-5 weeks postpartum, and found no significant increase above the values recorded in these same animals when pregnant (pregnant: $n=3,2.6 \pm 0.6 \mathrm{ng} \mathrm{ml}^{-1}$, range $0.9-7.4 \mathrm{ng} \mathrm{ml}^{-1}$; postpartum: $n=3,3.5 \pm 0.4 \mathrm{ng} \mathrm{ml}^{-1}$, range $2.8-4.1 \mathrm{ng} \mathrm{m}^{-1}$ ). This indicates that stress was not responsible for the postpartum decrease in sleep behaviour.

Four dolphins (Tursiopstruncatus) and their calves were also observed after birth and showed a similar pattern of sleep behaviour (Fig. 1b). Neither mothers nor calves rested at the surface during the first postpartum month, but time spent resting then gradually increased towards that spent by normal adults. As in the case of the killer whales, the neonates always showed less rest behaviour than the mothers.

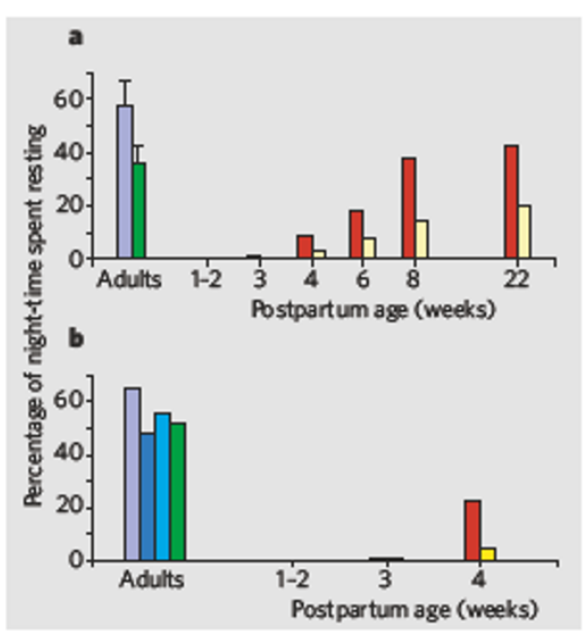

Figure 1 | Duration of rest behaviour in whales and dolphins. a,b, Time spent by killer whales floating at the surface and lying on the bottom of the pool (a) and by bottlenose dolphins floating at the surface (b). The data represent percentages of the night, the main sleep period in captive cetaceans. Data for one non-pregnant orca female and one adult male are the averages (with s.e.m.) of 12 nights ${ }^{10}$. All other killer-whale, dolphin and calf data are averages over two consecutive nights. Red, mothers; yellow, calves; blues, adult females without calves; green, adult males.

Administration of cortisol to an adult male and to an adult female dolphin (0.4-0.8 mg per $\mathrm{kg}$, twice a day) and administration of oxytocin - a hormone that increases with parturition and lactation - to another adult female dolphin ( $0.1 \mathrm{mg}$ per $\mathrm{kg}$, twice a day) produced non-significant increases or no change in the amount of sleep (results not shown).

When the dolphin and killer-whale neonates surfaced to breathe at intervals of $3-30 \mathrm{~s}$, the mother typically continued swimming, forcing the neonate to track her movements and catch up. The non-circular shapes of all but one of the pools housing the dolphins and killer whales, the tendency of the animals to stay within 1-3 m of the walls, and the presence of other animals in the pool (often swimming in opposite directions), as well as frequent breathing in the neonate, all necessitated much turning and surfacing by the postpartum cetaceans. These activities are incompatible with sustained periods of sleep.

We have previously reported that unihemispheric slow waves in the brains of dolphins and beluga whales (Delphinapterus leucas) are invariably linked to closure of the contralateral $e^{2 y e^{5.6}}$. We found that unilateral or bilateral eye closure was almost never (for less than $0.4 \%$ of $24 \mathrm{~h}$ ) observed in dolphin mothers during the first 2 months postpartum. The calves showed unilateral eye closure rarely (for less than $1.5 \%$ of the time) at less than 1 month of age. This amount increased to $16 \%$ of the time at 3 months, with the open eye nearly always (95-99\% of the time) being directed towards the mother.

We conclude that, although brief periods of slow-wave activity may have occurred, they would have been few; in the calves, they could not have exceeded $30 \mathrm{~s}$ before 1 month postpartum. This is surprising as interrupted sleep in humans and rats is known to be largely non-restorative ${ }^{7,8}$.

The ability to remain active and responsive after birth has several advantages for newborn cetaceans. Motor activity reduces predation and helps to maintain body temperature until their body mass has increased and insulating blubber develops. Surfacing for respiration occurs at shorter intervals in neonates compared with adults and disrupts sleep. The growth of the brain and body and correlated behavioural development in these cetaceans progresses with minimal resting behaviour, in contrast to the pattern seen so far in other animals, from flies ${ }^{9}$ to mammals ${ }^{2}$.

Oleg Lyamin ${ }^{\star} \dagger$, Julia Pryaslova†,

Valentine Lanceł , Jerome Siegel ${ }^{\star}$

*University of California, Los Angeles\& VA GLAHS, Sepulveda, NorthHills, Califomia 91343, USA e-mait: jsiegel@ucla.edu

†Utrish Dolphinarium, Moscow 119071, Russia

$\ddagger$ San Diego State University, San Diego,

California 92182, USA

1. Hoppenbrouwers T. \& Sterman, M. B. Exp Neural.49, 822-838 (1975).

2. Roffwerg H.P, Muzio, I. N. \& Dement, W.C. Science152, 604-619 (1966).

3. Shaw, P. L, Tononi, G, Greenspan, R. L \& Robinson, D. F. Nature 4T, 287-291 (2002)

4. Rechtschaffen, A, Gilliland, M.A, Bergmann, B. M. \& Winter, L B Science 221, 182-184 (1983).

5. Lyamin Q L etal. Behav. Bain Res. 129, 125-129 (2002).

6. Lyamin OL, Mukhametox, L. M. \& Siegel, J.M. Axch Ital. Biol. 142, 557-568 (2004).

7. Bonnet, MH. Physial. Behax 45, 1049-1055 (1989).

8. Rechtschaffen, A. \&Bergmann, B.M. Sleep 25, 18-24 (2002).

9. Shaw, P. L, Cirelli, C, Greenspan, R. L\& Tononi, G.Science 287, 1834-1837 (2000)

10. Flanigan, W.F.Sleep Res. 4, 139 (1975).

Sup plementary information accompanies this commun ication on Nature's webs ite. Competing fin ancial interests: declared none. doi:101038/4351177a 